\title{
VISIÓN DE ALFONSO REYES: EN BUSCA DE UNA EXPRESIÓN AMERICANA
}

\author{
Edison Aladino \\ Magister en Literatura \\ de la Benemérita Universidad Autónoma de Puebla
}

Resumen: El presente trabajo analiza el pensamiento americanista de Alfonso Reyes a través de la estructuración y desarrollo del concepto de "inteligencia americana". Reyes elabora este concepto como una respuesta a sus preocupaciones sobre la identidad del escritor latinoamericano. Dicho empeño inicia con Visión de Anáhuac, se consolida después en $A$ vuelta de correo y cobra sistematicidad conceptual en Última Tule. En este artículo se presentan y sustentan las ideas del autor mexicano en cuanto a una búsqueda cultural latinoamericana en relación con su obra y su construcción como escritor.

Palabras clave: Alfonso Reyes; "inteligencia americana"; Visión de Anáhuac; A vuelta de correo; Última Tule.

Recibido: 18 de septiembre de 2015

Aprobado: 20 de mayo de 2016

\section{Alfonso Reyes's Vision: in SEARCh of AN AMERICAN eXPRESSION}

Abstract: The next work analyzes Alfonso Reyes's American thought on the development and structure of the concept of 'American intelligence'. Reyes develops this concept in response to his preoccupations around the identity of the Latin American writer. His efforts start with Visión de Anáhuac, find consolidation in A vuelta de correo, and reach systematic conceptualization in Última Tule. This article presents and sustains the ideas of the Mexican author concerning the search for a Latin American culture in relation to his work and his own construction as a writer.

Keywords: Alfonso Reyes; 'American intelligence'; Visión de Anáhuac; A vuelta de correo; Última Tule.

*Edinson Aladino: Licenciado en Literatura de la Universidad del Valle (Cali, Colombia). Es Maestro en Literatura Mexicana, mención cum laude, de la Benemérita Universidad Autónoma de Puebla (Puebla, México). Actualmente cursa su segundo semestre del Doctorado en Letras de la UNAM (D.F., México). 


\section{EDISON ALADINO}

La misma circunstancia negativa de que hayamos sido mucho tiempo pueblos de cultura colonial o importada, nos adiestró para buscar fuera de nuestras fronteras los elementos indispensables a nuestra representación del mundo. Alfonso Reyes, Tentativas y orientaciones.

Para Alfonso Reyes el espacio de la condición latinoamericana radica en vivir al borde de dos culturas: la precolombina y la europea. Esto le da al escritor latinoamericano un poder de síntesis al no ser un producto directo de ninguna de las dos tradiciones. Reyes define esta perspectiva como "inteligencia americana", que viene hacer una especie de libertad creativa que le permite al artista manejar ambos legados culturales. Aquí no coexiste ningún exceso de reverencia frente a lo europeo, tampoco una "afectación arbitraria o un alarde romántico" (Borges, 1996: 281) frente a lo indígena. Esta búsqueda intelectual llevó al escritor regiomontano a reflexionar sobre el marco de su condición en la periferia ${ }^{1}$. El sentido de la escritura se trasluce en él como un atisbo íntimo y humano por sentar las bases en torno a una problematización del pensamiento americano.

Alfonso Reyes no renuncia a su circunstancia histórica. Tampoco renuncia a relacionar (o a vincular) dicha circunstancia con la más amplia tradición europea. Como lo señala Ramón Xirau: "Reyes se sitúa entre aquellos que podemos llamar maestros del pensamiento americano, llámense Rodó, Emerson o Andrés Bello" (1996: 293). La perspectiva de Reyes desemboca en una de sus mayores inquietudes: el tema de la identidad de los escritores latinoamericanos. El concepto de "inteligencia americana" es la concreción de una búsqueda de identidad cultural y a la vez es el motor de todo el proyecto literario, humanístico e intelectual alfonsino. El origen y estructuración de este concepto

\footnotetext{
${ }^{1}$ El concepto de centro y periferia es asumido aquí como el propio Reyes lo establece. Para él América Latina debía proyectarse de cara a un internacionalismo de la cultura, en la que alcanzara una "mayoría de edad" suficiente para superar el lugar periférico o la marginalidad que ocupaba el continente. Como latinoamericanos nacemos en un suelo que no es el foco de la "civilización", que no es el centro de la cultura. Esto nos da un terreno de ampliación e intervención para proponer cuestionamientos acerca de las condiciones en las cuales vivimos, determinados por una hibridación social que no hace parte de las categorías mono-céntricas europeas, pero que al mismo tiempo nos determinan para ejercer una revisión y reconstrucción de las diferencias sociales en el sentido de interrogar nuestras representaciones culturales.
} 
inicia con Visión de Anáhuac (1917), se explícita en A vuelta de correo (1932) y adquiere corporeidad sistemática en Última Tule (1942). En el presente artículo me centraré en el análisis de esas tres obras con el objetivo de trazar la génesis del concepto de "inteligencia americana" y plantear una reconceptualización del pensamiento americanista de Reyes en relación con sus preocupaciones como escritor latinoamericano.

\section{Visión de Anáhuac: alta meseta donde se detienen nuestros ojos}

Visión de Anáhuac fue escrita en $1915^{2}$. En ese entonces Alfonso Reyes tenía veintisiete años y estaba exiliado en Madrid ${ }^{3}$. En Historia documental de mis libros, el mismo autor refiere que esa era una época llena "de pobreza y libertad", en la que:

Tras ese primer choque o forma de contacto con el ambiente, de que es testimonio mi librito Cartones de Madrid, instalado ya con mi familia, aunque modestísimamente, en la calle de Torrijos, el recuerdo de las cosas lejanas, el sentirme olvidado por mi país y la nostalgia de mi alta meseta me llevaron a escribir la Visión de Anáhuac (1990: 224).

Dicha obra es escrita desde el exilio, producto del alejamiento y la añoranza del país. En ella, Reyes se desplaza hacia los orígenes con una frescura prístina y se instala en el año 1519, época en la que los europeos ven por primera vez la gran Tenochtitlan ${ }^{4}$. El texto va más allá de una

\footnotetext{
${ }^{2}$ En 1911 Alfonso Reyes escribió una conferencia para representar al Ateneo de la Juventud en el Concurso Artístico y Científico del Centenario. Dicha conferencia llevaba por título: "El paisaje en la poesía mexicana del siglo XIX". (Recuperado en Capitulos de literatura mexicana, tomo I de las Obras Completas). En este texto el autor había anticipado varias reflexiones en torno a la importancia del paisaje en la literatura latinoamericana. Él mismo le refiere a Pedro Henríquez Ureña, en una carta fechada el 9 de noviembre de 1916, que ha tomado pasajes de este discurso para su Visión de Anáhuac: "Los ruidos oratorios se deben a los trozos de la antigua conferencia sobre el paisaje que aproveché sin corregir más que lo muy absurdo" (citado en Castañón, 2012: 216-17).

${ }^{3}$ Alfonso Reyes había salido de México en julio de 1913, tras la muerte de su padre, el General Bernardo Reyes, gobernador porfirista del Estado de Nuevo León, quien fue asesinado en un fallido golpe de Estado contra el presidente Francisco Madero en febrero del mismo año. Victoriano Huerta, quien usurpó el poder, intentó seducir al joven Alfonso con un cargo de secretario personal. Pero "cuando Reyes se negó, Huerta le sugirió que se diera un "paseíto" por el extranjero, proporcionándole una posición en la delegación mexicana de París" (Faber, 2004: 22). A Reyes lo despidieron en octubre de 1914 de la embajada mexicana en Francia y decidió instalarse en Madrid, fiel a la voluntad de seguir su camino de escritor (Barili, 1999:132).

${ }^{4}$ Visión de Anáhuac suscita varias posibilidades de lectura; igualmente, las interpretaciones
} 
apología lírica, de una contemplación estética del paisaje basada en la reminiscencia y la evocación. Reyes, alejado de México, sigue pensando en su "alta meseta"; medita sobre los rostros del ayer reflexionando sobre los rostros del presente. En una carta enviada a Antonio Mediz Bolio, que data de 1922, se vislumbra su inquietud constante por profundizar en la fisonomía y el carácter del alma nacional, en la cual Visión de Anáhuac se constituye como una cristalización primigenia de sus intenciones:

Yo sueño -le decía yo a usted- en emprender una serie de ensayos que habrían de desarrollarse bajo esta divisa: En busca del alma nacional. La Visión de Anáhuac puede considerarse como un primer capítulo de esta obra, en la que yo procuraría extraer e interpretar la moraleja de nuestra terrible fábula histórica: buscar el pulso de la patria en todos los momentos y en todos los hombres en que aparece intensificado; pedir a la brutalidad de los hechos un sentido espiritual, descubrir la misión del hombre mexicano en la tierra, interrogando en todos los fantasmas y las piedras de nuestras tumbas y nuestros monumentos (Alicia Reyes, 1997: 456).

Desde el exilio abre un espacio de interrogación inherente a la identidad del escritor latinoamericano. En el contacto de la experiencia vivida con la cultura ibérica, al tener una cercanía directa con Europa, empieza a preocuparse por su ser, por sus orígenes, evocando a los antiguos habitantes de Tenochtitlan. Es un extranjero, un peregrino, el "jinete del aire" (2003: 233) como lo llamaba Octavio Paz; pero lleva siempre consigo a México, el apego por su tierra natal. Amelia Barili señala que: "Reyes rinde homenaje a esa civilización desaparecida y establece un nexo entre el mexicano de hoy y los antiguos mexicanos,

\footnotetext{
que se proponen son diversas. Comenzando por la misma tipología de la obra. Jorge Mañach arguye que es "a reflective description of the Mexican plateau and its Aztec society at the time of the Conquistadores" (1996: 174); Jean Rose opina que es un "mirage prestigieux que s'annexe à l'imaginaire, l'histoire devient mythe" (1996: 734-41); Luis Leal sugiere que en la obra "no se rechaza ni la poesía ni la documentación" (1996: 768); para James Robb es un "bello ensayo poemático" (1996: 995); Rangel Frías lo califica de "alto poema dramático" (1997: 438); y Juan José Domenchina de "poema genesíaco" (1996: 461). Ha sido calificado de "poema en prosa, ensayo poético, texto histórico-lírico, obra de arte, etc." (Alicia Reyes, 1997: 455). No nos adentraremos en esos escarceos taxativos, aunque consideramos valioso mencionarlos. Lo que nos interesa, en específico, es analizarla en función del pensamiento americanista reyesiano.
} 
unidos en un "alma común", por la misma emoción cotidiana ante el mismo suelo" (1999: 125).

Lo que podemos inferir a través de la carta de Reyes y del comentario de Barili, es que Visión de Anáhuac se erige como un intento por esclarecery definir la identidad mexicana a partir de una reinterpretación histórica, llevada a cabo por una perspectiva americana. Su condición le permite no sólo interpretar el legado cultural del México precolombino, la imagen proyectada por las crónicas de los conquistadores, sino apropiarse de él y reescribirlo desde Madrid ${ }^{5}$. Es lo que él mismo señala como "retorno transformador", en el que a través de un proceso arqueológico se va reconstruyendo una autonomía, que viene a ser la "palabra propia".

Visión de Anáhuac está dividida en cuatro partes. En ella hay una integración de elementos dispares que afloran en una estructura armónica. Nos encontramos por un lado con crónicas, historias, documentos y poesía en los que se describe el Valle de México; por otro, con referencias a Cortés, Moctezuma, Bernal Díaz y Netzahualcóyotl, hasta llegar a poetas como Keats y Darío. En la primera parte se introduce el tema: el Valle de Anáhuac, "la región más transparente del aire" (1995: 13). Aquí se describe el paisaje mexicano a partir de cuatro aspectos: las plantas, los lagos, la meseta mexicana y el mundo de los aztecas. Todo en relación con una descripción unificada de la vegetación del territorio precolombino: "Deténgase aquí nuestros ojos: he aquí un nuevo arte de naturaleza" (1995: 14).

En la segunda parte nos encontramos en la ciudad de Tenochtitlan. La prosa aquí se deja llevar por la hipérbole, en confluencia con los

\footnotetext{
${ }^{5}$ Robert Conn reconstruye la influencia de Alfonso Reyes en la llamada Generación del 98 a la vez la cadencia de sus pasos por la península ibérica, aludiendo al tema del exilio como "la condición para la escritura, el contexto en el cual y a partir del cual el emigrado integra conscientemente narrativas que explican la identidad de Latinoamérica junto con la de su nación individual" (2004: 112-13).

${ }^{6}$ La actividad febril que vive en España entre 1914 y 1919, amparado en los recursos de su vocación por las letras, donde "traduce, corrige, prepara ediciones de clásicos, pero sobre todo escribe y transcribe" (Castañón, 2012: 184), le sirven para afianzar su carrera artística y de paso elaborar una pesquisa de identidad. En ese espacio ibérico, circundado por intelectuales de renombre como Azorín, Unamuno, Valle-Inclán y el mismo Ortega y Gasset, se confina en la filología en el Centro de Estudios Históricos animado por Ramón Menéndez Pidal. Desde el exilio no olvida a México ni a América Latina. No en vano la filología le depara el encuentro con documentos y crónicas de la época de la Nueva España.
} 


\section{EDISON ALADINO}

hombres de Cortés (que hablan a través de Bernal Díaz), cuyo asombro se acrecienta a cada paso por las calles, las casas, los palacios y el templo. La palabra se extiende hacia todos los elementos que componen la ciudad: animales, alimentos, adornos, ropajes, colores, entre otros. Para demostrar que "lo nuestro, lo de Anáhuac, es cosa mejor y más tónica" (1995: 16).

En la tercera parte el interés se dirige hacia la flor: la flor en el arte azteca, la flor tenida en cuenta como elemento constitutivo de la poesía náhualt. Como lo señala Rangel Guerra, la flor es el centro de la "expresión de la poesía, como testimonio de la belleza, como presencia total en la vida indígena mexicana" (1997: 450). En esta parte Reyes acoge la sensibilidad, la belleza y el sentido del alma indígena, cuyo reflejo preclaro es la poesía. Asimismo, describe cómo el conquistador prohibió al indígena sus cantos, enlazados a su visión religiosa del mundo, extinguiéndose así la grandeza y maravilla de toda una cultura viva: "Hay que lamentar como irremediable la pérdida de la poesía indígena mexicana. Podrá la erudición descubrir aislados ejemplares de ella o probar la relativa fidelidad con que algunos otros fueron romanceados por los misioneros españoles" (Reyes, 1995: 29).

En la cuarta y última parte, Reyes concluye su Visión abriendo el camino con una intervención creativa hacia nuevas posibilidades de pensar las condiciones o procesos en los que se producen las articulaciones de las identidades culturales. Su interpelación gira en torno al significado de un pasado histórico en relación con nuestro presente:

Nos une con la raza de ayer, sin hablar de sangres, la comunidad del esfuerzo por domeñar nuestra naturaleza brava y fragosa (...) Nos une también la comunidad, mucho más profunda, de la emoción cotidiana ante el mismo objeto natural. El choque de la misma sensibilidad con el mismo mundo labra, engendra un alma en común (1995: 34).

Alfonso Reyes va en busca de un tiempo perdido: se remonta a su pasado precolombino, lo revive a través de su prosa para contemplar un tiempo recobrado, que coexiste con su preocupación ontológica, con la construcción de su propia identidad americana. A través de la 
experiencia vivida y la cultura asimilada, recrea su visión sobre el México antiguo. Lo que nos muestra Reyes es una nueva forma de mirar ese suelo mexicano, de reconstruirlo e identificarse con él. Es un reconocerse a partir de la propia mirada, una mirada íntima y personal. Visión de Anáhuac es el punto inicial en el que Alfonso Reyes traza una representación sobre la conciencia de su tradición americana. Él aprovecha ese legado, lo hace suyo, y da un paso hacia adelante. Reescribe, recrea y celebra "la continuidad de las raíces de nuestra cultura fincadas en ese pasado remoto y un presente eterno" (Xirau, 1996: 442).

\section{A vuelta de correo: la americanía andante de Alfonso Reyes}

Los años vividos en España acercaron a Alfonso Reyes con el "ayer de su sangre y una noble curiosidad lo hizo ahondar en el ayer latino y helénico" (Borges, 1996: 282). No obstante, se le reprochó su afición por Grecia como "huida y hasta rechazo y desprecio de los problemas de su patria" (Gutiérrez Girardot, 2004: 4), acusándosele de estar desconectado de México y de no "contribuir a la búsqueda de la identidad mexicana por tener sus miras puestas en la tradición cultural europea" (Barili, 1999: 120). En el ambiente político y social en el que se le hicieron estas acusaciones, ${ }^{7}$ se abogaba por una literatura nacional. Lo cierto es que Reyes nunca quiso conjuntar su trabajo literario con una estrechez cultural que lo relegara solamente a la exaltación de un regionalismo anquilosado. Desde muy temprano actuó con una resuelta disposición por renovar -con sus compañeros del Ateneo de la Juventud- el panorama literario de México, en un empeño por instaurar "un cosmopolitismo de la cultura de las humanidades" (Gutiérrez Girardot, 2004: 2).

En medio del clima político de los años treinta en México, Reyes es interpelado por su presunta desvinculación con su país y alejamiento de las letras mexicanas. La acusación la realiza un joven del periódico $E l$

\footnotetext{
${ }^{7}$ A Alfonso Reyes le tocó vivir una época de crisis ontológica, en medio de una transición histórica mediada por la Revolución mexicana, que suscitó la búsqueda de una identidad, exacerbando la pasión por el nacionalismo y desestructurando los esquemas anteriores que se habían formado en torno a la construcción de una imagen que representara los valores idiosincráticos inherentes al país.
} 
Nacional, Héctor Pérez Martínez, en una columna del 7 de mayo de 1932. El escritor regiomontano refuta la inculpación de "lesa mexicanidad" (Faber, 2004: 22) en A vuelta de correo. El tema central de la réplica reyesiana es la polarización entre nacionalismo y/o cosmopolitismo:

Ninguna interpelación puede preocuparme ni conmoverme más; pero me temo que Pérez Martínez haya sido dos veces injusto: por el reproche de alejamiento que me hace, y por la consideración desmedida que me concede, hija de una simpatía con ribetes de intolerancia (...) En todo este tiempo, he publicado muchos libros de prosa y unos pocos de versos. Quien tuviera la paciencia de examinarlos, fácilmente se convencerá de que no hay uno solo en que no aparezcan el recuerdo, la preocupación o la discusión directa del tema mexicano (1996: 428).

Reyes cierra la dicotomía entre nacionalismo y cosmopolitismo con una soltura mediada por el equilibrio, en donde lo último no se opone a lo primero, sino que viene a ser su manifestación acorde. El aislamiento y el confinamiento cultural para Alfonso Reyes no era un desvelo; lo que realmente le interesa es el derecho a tomar de Europa todo lo que sea necesario, a gozar de los beneficios que ese legado pueda ofrecerle. Él permanece abierto al diálogo con otras tradiciones, combatiendo el aislacionismo o provincialismo. El sentido de la inteligencia, como lo decanta el autor, tiene una función unificadora, acogiendo todas las conquistas, realizando una labor de síntesis:

Yo estudio tanto lo nacional como lo extranjero, es natural que allí aparezca el reflejo de todas las zonas de mi trabajo, y no veo dónde está mi falta. ¡No me hagan pensar en el que creía que leer libros franceses, cuando se nació hablando español, es un rasgo de vanidad y un síntoma de insuficiencia! ¿De modo que por ser mexicano tengo que desentenderme de lo demás? Al contrario: a México le conviene que se oiga su voz en todas partes (1996: 436-39).

En A vuelta de correo vemos el quehacer literario de Alfonso Reyes como una contribución por trazar una "memoria cultural del continente" (Corral, 2004: 171), de abrir caminos y preguntas en torno a qué significa ser un escritor latinoamericano. Reyes desarrolla su propia americanía andante, al mismo tiempo que rinde un servicio esencial 
a su país. Sin embargo, él va más allá de las murallas nacionales. Busca el equilibrio, la armonía. Su pensamiento está dotado de un apetito universal que lo obliga a buscar las razones de su acción y de su cultura con una elasticidad plena, que lo confina a observar la vasta herencia cultural del mundo con un sentido de unidad y conjunción. Es la capacidad de retomar toda esa herencia para forjar su propio destino como un proyecto, como una empresa que va realizando de forma cabal y auténtica de acuerdo a las circunstancias en las que se inscribe su vocación personal.

\section{3. Última Tule: la utopía literaria de Alfonso Reyes}

La preocupación por el espíritu de América en Alfonso Reyes se ve reflejada en gran parte de su obra. Sin embargo, es en Última Tule (1942) en donde reflexiona sobre ello con un sentido histórico, literario y filosófico ${ }^{8}$. Esta obra comprende una serie de ensayos en los que el autor define su idea utópica del continente americano; idea que nos habla del "compromiso del escritor con el destino del continente" (Corral, 2004: 173). Lo que se propone es hablar de "inteligencia americana" para poder definir el contorno de América: "Llegada tarde al banquete de la civilización europea, América vive saltando etapas, apresurando el paso y corriendo de una forma en otra, sin haber dado tiempo a que madure del todo la forma precedente" (Reyes, 1997a: 82-3).

El escritor americano, como lo anota Reyes, hace un esfuerzo por contrarrestar las lagunas de su formación debido a sus condiciones geoculturales. Está llamado a desempeñar una función complementaria: erigir síntesis, avanzando con un sentido de asimilación y apropiación ${ }^{9}$, que converge en "un equilibrio que se resuelve en una peculiar manera

\footnotetext{
${ }^{8}$ En pleno contexto del totalitarismo occidental, de la Guerra Civil Española, Alfonso Reyes lee sus "Notas sobre la inteligencia americana" en la VII Conversación del Instituto Internacional de Cooperación Intelectual, llevada a cabo en Buenos Aires del 11 al 16 de septiembre de 1936.

${ }^{9}$ En esta actividad desbordante, del incesante quehacer intelectual alfonsino, también encontramos otros datos claves, como lo señala Virginia Aspe, que ayudaron a ensanchar su panorama humanístico: "A don Alfonso le configuró su inteligencia el haber sido miembro del servicio diplomático mexicano. Ese oficio no sólo lo refinó más en sus modales y maneras facilitándole relaciones culturales extranjeras de primer orden, sino que modeló su inteligencia de un modo más institucional y frío, desapegado del impulso emocional que tanto le jalaba por la palabra poética, dándole pausa y reflexión, y una experiencia universal de talante filosófico" (2004: 13).
} 
de entender el trabajo intelectual como servicio público y como deber civilizador" (1997a: 86). Pedro Henríquez Ureña resalta que todo aislamiento es ilusorio, pues "no sólo sería ilusorio el aislamiento la red de las comunicaciones lo impide-, sino que tenemos derecho a tomar de Europa todo lo que nos plazca: tenemos derecho a todos los beneficios de la cultura universal" (1960: 29). La armonía de la "inteligencia americana" que se denota aquí comporta una mentalidad dinámica: a la vez que está arraigada en su tierra, se mueve con una naturalidad internacionalista:

Esto se explica, no sólo porque nuestra América ofrezca condiciones para ser el crisol de aquella futura "raza cósmica" que Vasconcelos ha soñado, sino también porque hemos tenido que ir a buscar nuestros instrumentos culturales en los grandes centros europeos, acostumbrándonos así a manejar las nociones extranjeras como si fueran cosa propia. En tanto que el europeo no ha necesitado de asomarse a América para construir su sistema del mundo, el americano estudia, conoce y practica a Europa desde la escuela primaria (Reyes, 1997a: 87).

$\mathrm{Al}$ americano, nacido y arraigado en un suelo que no es el foco de la civilización, lo que le queda es salir de las "fatalidades de la cárcel concéntrica" (1997a: 88) en la que está y asumir la síntesis de su cultura como punto de partida. La "inteligencia americana" no es regional. Su empeño va más allá del autoctonismo exacerbado; anida en ella, en cambio, un internacionalismo dialógico en el que América no se limita a América. Reyes se sirve de esta idea para forjar una búsqueda de identidad, para plantearse un problema inherente a su labor como humanista. Por ello acoge "la imagen europea del Nuevo Mundo como camino para aproximarse a la esencia americana, como medio para entender mejor lo que es la esencia americana" (Houvenaghel, 2003: 153).

La "inteligencia americana" es un concepto en el que se ve representada la condición del escritor latinoamericano y su posibilidad de sintetizar legados culturales a través de un ejercicio de apropiación, para crear una esfera de pensamiento e identidad. En el orden histórico de la voluntad utópica de Reyes se traza la exploración de la propia 
originalidad sirviéndose de los presupuestos discursivos del universo occidental, a fin de "conocer la fisonomía que damos como quien se estudia en el espejo" (Reyes, 1989: 433-4). Esto constituye una cara doble del proceso en el que la "inteligencia americana" busca y consolida su autonomía. La otra es complemento de la primera, consiste en el proceso gradual de apropiación de la tradición, con el cual el proyecto americano sienta las premisas para hablar en los mismos términos a la cultura europea. La asimilación del recorrido por cuenta propia deviene en la incursión de perfilar una palabra ajustada a la elaboración conceptual que surge a partir de tomar conciencia del espacio que se ocupa como escritor.

Este es uno de los aspectos que Octavio Paz resalta, refiriendo el equilibrio que cultivó Reyes al estudiar las disciplinas más lejanas y las épocas más distantes:

Reyes enamorado de la mesura y la proporción, hombre en el que todo, inclusive la acción y la pasión, debería resolverse en equilibrio (...) La literatura griega no le reveló una filosofía, una moral, un "deber ser" sino al ser mismo en su marea, en su ritmo alternativamente creador y destructor (...) Ética y estética se enlazan en el pensamiento de Reyes: la libertad es un acto estético, es decir, es el momento de concordia entre pasión y forma, energía vital y medida humana; al mismo tiempo, la forma, la medida, constituyen una dimensión ética, ya que nos salva de la desmesura que es caos y destrucción (2003: 226-233).

En Alfonso Reyes converge el sentido clásico de la palabra humanitas, entendida como una preferencia hacia la armonía, el equilibrio y el orden. Su vocación, intención y naturaleza, lo llevaron a descubrir nuevas interpretaciones de nuestra realidad cultural. Se ejercitó en el cultivo de sí mismo a través de una comprensión profunda de su condición histórica y social. Su vocación humanista lo llevó a asumir tanto el interés particular como el colectivo: lo propio en cuanto individuo, en cuanto mexicano, y el servicio universal, la preocupación constante en cuanto a lo que significa ser y escribir desde América.

Reyes se adecua a la realidad en la que vive e intenta renovar la tradición literaria del continente con el testimonio de su obra. Desde muy temprano, con Cuestiones estéticas (1911), había delineado el mapa 
de sus propósitos como escritor e intelectual. Luego, desde España, hace una reconstrucción histórica y poética de la primera imagen que tuvieron de la tierra americana los conquistadores. En su peregrinaje como diplomático por distintos países (Francia, Buenos Aires, Río de Janeiro, entre otros) acentúa su conciencia latinoamericana movido por el afán de mantenerse al tanto del ambiente literario de su país y a la vez trabajando arduamente en la construcción de su identidad como escritor, de su legado inherente a la realización de su pensamiento americano. Reyes mantuvo siempre encendida la antorcha en la que ardían impulsos de descontento y esperanzas de una promesa, que junto a Pedro Henríquez Ureña y Antonio Caso habían inaugurado a principios del siglo XX: "el empeño por reorganizar la vida espiritual y cultural de México y de Latinoamérica" (Gutiérrez Girardot, 2004: 5).

\section{Palabras al cierre: concreción de una búsqueda cultural}

En Alfonso Reyes nunca hubo ausencia de sentido humanístico. Dentro de sus proyectos siempre estuvo difundir en tierras extranjeras el panorama de la literatura mexicana y a la vez contribuir a ese panorama con sus mismos escritos. Lejos de su país, recorre y vivifica su raíz mexicana, la tradición europea y la de su propio continente. Como intelectual americano exiliado, observa su destino y cree que la realización individual es el motor de su papel activo en el proceso de formación cultural de Latinoamérica: "intelectual periférico en la tradición occidental, cuyo movimiento crítico radica no en la constitución de un sistema de signos que dé cuenta legítima de la "nación", sino de una ontología crítica del movimiento mismo de su historia" (Sánchez Prado, 2002: 64).

En la voluntad utópica de Alfonso Reyes también sobresale su propia búsqueda de identidad, inquisiciones acerca del lugar que ocupa como latinoamericano en el espacio de la cultura universal. La evolución del concepto de "inteligencia americana" va en relación con la situación histórica del escritor regiomontano. Hemos trazado un hilo conductor que parte de las preocupaciones por su pasado azteca (Visión de Anáhuac), pasando por una discusión literaria entre nacionalismo y 
cosmopolitismo ( $A$ vuelta de correo), hasta llegar a la indagación de América y el lugar que ocupa dentro de la cultura universal (Última Tule).

La "inteligencia americana" nos invita al diálogo. A un diálogo de intervención a fin de solventar nuestras diferencias culturales con base en una armonía internacional. Las circunstancias de vivir en América Latina nos han llevado a buscar fuera de nuestro propio espacio, más allá de los límites de nuestro territorio, los "elementos indispensables a nuestra representación del mundo" (Reyes, 1997: 334). No obstante, sintiéndose heredero de un compromiso abrumador con la cultura en nuestra América y llamado a continuarlo, Alfonso Reyes expone su palabra y nos manifiesta que ha llegado el turno de hablar por sí mismos, de pensar por sí mismos.

Lo que le interesa es plantear el quehacer intelectual autónomo en América Latina y asumir esa condición, superando cualquier marginalidad en la disposición del discurso. Su inquietud es enfrentar esta cuestión realizando un dialogismo con la tradición cultural de Occidente, para rescatar la idea del "sujeto intelectual como totalizador de la experiencia" (Moraña, 1984: 71), recogiendo las letras clásicas, los nuevos métodos críticos y filosóficos, y así intervenir en el campo cultural del universo literario. Si Alfonso Reyes incorpora, en su acervo literario, los temas grecolatinos ${ }^{10}$, las cuestiones literarias y filosóficas de distintas tradiciones, no es para emplear su erudición en aras a una distinción intelectual, sino para enfocar y erigir la "inteligencia americana" como función, acción y toma de posición en el marco de la "república internacional de las letras" (Casanova, 2001: 25).

Él construye su perspectiva americanista entre 1920 y 1942, en un período en el que Europa "había fracasado en asegurar la paz mundial y amenazaba con caer en manos del fascismo. En no pocos círculos intelectuales se hablaba ya de la "fatiga espiritual" de Europa y se discutían las ideas de Spengler sobre la Decadencia de Occidente"

\footnotetext{
${ }^{10}$ En Reyes lo grecolatino hace parte de su idea central sobre el humanismo, en vías a una recuperación direccionada hacia un espacio pragmático del intelectual latinoamericano. Gutiérrez Girardot especifica que el autor "actualiza valores griegos, pero sin ánimo nostálgico. Su Grecia no es como la del "neohumanismo" alemán, una Grecia idealizada y refugio del presente, con la que se mide negativamente el mundo actual. Su Grecia es ejemplar porque no sólo creó la idea del hombre, sino porque padeció problemas que también conoce el mundo contemporáneo" (2004: 13).
} 
(Castro-Gómez, 2004: 55). Las condiciones de decadencia espiritual europeas de la época hacen que Reyes piense en América Latina como "el último reducto de lo humano" (1997b: 111), cuyo deber es hacerse cargo, dado el desastre total de Europa en el despliegue del fascismo y la Segunda Guerra Mundial, de la herencia de la civilización.

Reyes se considera heredero de una larga tradición literaria y a la vez un humanista activo, que revivifica su patrimonio literario sirviéndose de él como participante de la cultura universal, para direccionar toda esa experiencia en la posibilidad de reconfigurar una verdadera conciencia intelectual. Por ello, asumió la dimensión de la escritura como síntesis de una vocación internacionalista, de una búsqueda de expresión propia, auténtica, por consolidar una identidad e independencia cultural: "Y ahora yo digo ante el tribunal de pensadores internacionales que me escucha: reconocemos el derecho a la ciudadanía universal que ya hemos conquistado. Hemos alcanzado la mayoría de edad. Muy pronto os habituareis a contar con nosotros" (Reyes, 2015).

\section{Bibliografía}

Aspe Armella, V. (2004). “Alfonso Reyes", Enciclopedia mexicana del siglo $X X$. México D.F.: Instituto de Investigaciones Filológicas de la Universidad Nacional Autónoma de México.

Barili, A. (1991). Jorge Luis Borges y Alfonso Reyes: la cuestión de la identidad del escritor latinoamericano. México D.F.: Fondo de Cultura Económica.

Borges, J.L. (1996). “Alfonso Reyes”, En Más páginas sobre Alfonso Reyes, volumen III, (James Willis Robb, comp,), México: El Colegio Nacional, pp. 281-283.

Bourdieu, P. (2002). Razones prácticas. (Thomas Kauf, trad.). Barcelona, España: Anagrama.

Casanova, P. (2001). La República mundial de las Letras. (Jaime Zulaika, trad.). Barcelona, España: Anagrama.

Castañón, A. (2012). Alfonso Reyes: caballero de la voz errante. México D.F.: Universidad Autónoma de Nuevo León.

Castro-Gómez, S. (2004). "América Latina y la nueva mitología de la razón: el proyecto americanista de Alfonso Reyes", En Alfonso Reyes y los estudios latinoamericanos (Adela Pineda Franco e Ignacio Sánchez Prado, eds.). México D.F.: Serie Críticas, pp. 51-62.

Conn, R. (2004). "Reconstruyendo la cultura desde España: la Revolución Mexicana y la Generación del 98", En Alfonso Reyes y los estudios 
latinoamericanos (Adela Pineda Franco e Ignacio Sánchez Prado, eds.). México D.F.: Serie Críticas, pp.105-129.

Corral, R. (2004). “Alfonso Reyes y la cuestión del americanismo", En Alfonso Reyes y los estudios latinoamericanos (Adela Pineda Franco e Ignacio Sánchez Prado, eds.). México D.F.: Serie Críticas, pp.171-187.

Domenchina, J. J. (1996). "Alfonso Reyes y su Visión de Anáhuac", En Páginas sobre Alfonso Reyes I (Alfonso Rangel Guerra, comp.). México D.F.: El Colegio Nacional, pp. 460-475.

Faber, S. (2004) "Don Alfonso o la fuerza del sino: Reyes, la cultura latinoamericana y la defensa de la distinción", en Alfonso Reyes y los estudios latinoamericanos (Adela Pineda Franco e Ignacio Sánchez Prado, eds.). México D.F.: Serie Críticas, pp. 14-48.

Rangel Frías, R. (1997). "Reyes y su Visión de Anáhuac", En Páginas sobre Alfonso Reyes IV (James Willis Robb, comp.). México D.F.: El Colegio Nacional, pp. 437-444.

Gutiérrez Girardot, R. (2014). "La concepción de Hispanoamérica de Alfonso Reyes", en El Mausoleo Iluminado: antología del ensayo en Colombia, Biblioteca Virtual del Banco de la República, 2004, pp. 1-19, disponible en: banrepcultural.org, último acceso, octubre 2014.

Henríquez Ureña, P. (1960). Obra crítica. México D.F.: Fondo de Cultura Económica.

Houvenaghel, E. (2003). Alfonso Reyes y la historia de América. México D.F.: Fondo de Cultura Económica.

Leal, L. (1996). "La Visión de Anáhuac de Alfonso Reyes", en Páginas sobre Alfonso Reyes III (James Willis Robb, comp.). México D.F.: El Colegio Nacional, pp. 765-772.

Mañach, J. (1996). "In Price of the other America", en Páginas sobre Alfonso Reyes II (Alfonso Rangel Guerra, comp.). México D.F.: El Colegio Nacional, pp. 174-176.

Moraña, M. (1984). Literatura y cultura nacional en Hispanoamérica (19101940), Minneapolis: Institute for the Study of Ideologies and Literature.

Paz, O. (2003). "El jinete del aire: Alfonso Reyes", Obras Completas IV. México D.F.: Fondo de Cultura Económica.

Rangel Guerra, A. (1997). "Belleza y composición de Visión de Aná-huac", en Páginas sobre Alfonso Reyes, volumen IV (James Willis Robb, comp.). México D.F.: El Colegio Nacional, pp. 445-452.

Reyes, A. (1993). El deslinde: Prolegómenos a la teoría literaria. México D.F.: Fondo de Cultura Económica., México, 1983. (1989). Vocación de América, Antología (Víctor Díaz Arciniega, ed.).

México D.F.: Fondo de Cultura Económica. 
. (1992). "Cuestiones estéticas", Obras Completas I. México D.F.: Fondo de Cultura Económica.

. (1992). "Capítulos de literatura mexicana", Obras Completas I. México

D.F.: Fondo de Cultura Económica.

. (1990). "Historia documental de mis libros", Obras Completas XXIV.

México D.F.: Fondo de Cultura Económica.

. (2015). "Notas sobre la inteligencia americana". Proyecto Ensayo

Hispánico. Recuperado de http://www.ensayistas.org/antologia/XXA/ reyes/

. (1995). "Visión de Anáhuac", Obras Completas II. México D.F.: Fondo de Cultura Económica.

. (1996). "A Vuelta de Correo", Obras Completas VIII. México D.F.: Fondo de Cultura Económica.

. (1997a). "Última Tule", Obras Completas XI. México D.F.: Fondo de Cultura Económica.

. (1997b). "Tentativas y orientaciones", Obras Completas XI. México D.F.: Fondo de Cultura Económica.

Reyes, Alicia. (1997). "Evocación de Visión de Anáhuac”, en Páginas sobre Alfonso Reyes, volumen IV (James Willis Robb, comp.). México D.F.: El Colegio Nacional, , pp. 453-460.

Robb Willis, J. (comp.) (1996). “En busca de la región más transparente del aire de Alfonso Reyes”, en Páginas sobre Alfonso Reyes III. México D.F.: El Colegio Nacional, pp. 995-1014.

Rose, J. (1996). "Lecture de Visión de Anáhuac", en Páginas sobre Alfonso Reyes III (James Willis Robb, comp.). México D.F.: El Colegio Nacional, pp. 734-741.

Sánchez Prado, I. (2002). Naciones intelectuales: La modernidad literaria mexicana de la constitución a la frontera (1917-2000). Pittsburgh: Universidad de Pittsburgh.

Xirau, R. (1996). "La Última Tule de Alfonso Reyes", en Páginas sobre Alfonso Reyes, volumen III (James Willis Robb, comp.). México D.F.: El Colegio Nacional, pp. 293-299. 